\title{
Mass Spectrometric Research of Hydrogenated Molecules of Carbon as Products of Pyrolysis of Benzene and Pyridine Vapours
}

\author{
Alexey Kharlamov ${ }^{1}$, Marina Bondarenko, ${ }^{1, *}$, Ganna Kharlamova ${ }^{2}$ \\ ${ }^{1}$ Frantsevich Institute for Problems of Materials Science of NASU, Krzhyzhanovsky St. 3, 03680 Kiev, Ukraine \\ ${ }^{2}$ Taras Shevchenko National University of Kiev, Volodymyrs'ka St. 64, 01601 Kiev, Ukraine \\ *Corresponding Author: dep73@ipms.kiev.ua
}

Copyright $(\subseteq 2013$ Horizon Research Publishing All rights reserved.

\begin{abstract}
Hydrogenated carbon molecules are synthesized by a method which essentially is distinct from already known methods of preparation of fulleranes as this method a preliminary stage of synthesis of carbon molecules is excluded completely. Fulleranes and quasi-fulleranes as nanodimentional particles were in common deposited by ethanol from benzene-xylene extracts from products of pyrolysis of vapours of benzene and pyridine. The dehydrogenation of the synthesized samples of fulleranes and quasi-fulleranes is started at $30-50{ }^{\circ} \mathrm{C}$ and the evacuation of hydrogen proceeds up to $700{ }^{\circ} \mathrm{C}$. At thermolysis of nanopowders of fulleranes and quasi-fulleranes alongside with hydrogen are formed also hydrocarbons (methane, propane and butane), which are usually detected at defullerenization (disclosing and partial fragmentation of fullerene cage) fulleranes, synthesized at hydrogenation of fullerenes or fullerite. The contents of hydrogen in some quasi-fulleranes $\left(\mathrm{C}_{26} \mathrm{H}_{24}, \mathrm{C}_{28} \mathrm{H}_{22}, \mathrm{C}_{30} \mathrm{H}_{22}\right)$ and fulleranes $\left(\mathrm{C}_{60} \mathrm{H}_{32}, \mathrm{C}_{60} \mathrm{H}_{46}, \mathrm{C}_{60} \mathrm{H}_{60}\right)$ reaches 5.4-6.9 mass\%. The first was detected by a mass spectrometric method the cluster $\mathrm{C}_{60} \mathrm{H}_{60}$, the thin structure of which spectrum completely corresponds fullerane of equiatomic composition, $\mathrm{C}_{60} \mathrm{H}_{60}$.
\end{abstract}

Keywords Pyrolysis, Fulleranes, Quasi-Fulleranes, Quasi-Fullerenes, Hydrides, Benzene, Pyridine

\section{Introduction}

Hydrides of fullerenes (or fulleranes [1]) as first derivatives of fullerene (obtained by Haufler [2] already after 5 years after opening by Kroto of a spheroidal molecule of carbon [3]) have attracted the special attention of the experts in the field of hydrogen power as, ostensibly, perspective and effective accumulators of hydrogen. It was supposed, that in case of synthesis of equiatomic fullerane $\mathrm{C}_{60} \mathrm{H}_{60}$ and following its complete dehydrogenation it would be possible to speak about creation on the basis of system of convertible reactions

$$
\mathrm{C} 60+30 \mathrm{H} 2 \rightleftharpoons \mathrm{C} 60 \mathrm{H} 60
$$

accumulator of hydrogen with so huge (7.7mass. \%) contents of hydrogen. Though here it is necessary to note, that in dodecahedrane $\mathrm{C}_{20} \mathrm{H}_{20}$, which was synthesized by Paquette [4] three years prior to opening of fullerene $\mathrm{C}_{60}$ (and 8 years prior to obtaining of first fullerane $\mathrm{C}_{60} \mathrm{H}_{36}$ ), the ratio $\mathrm{H} / \mathrm{C}$ is the same $(1 / 12)$ as in fullerene $\mathrm{C}_{60} \mathrm{H}_{60}$. However of so steadfast interest of the researchers this controllable synthesized hydride of fullerene for some reason had not and has not. The reasonable explanation of so selective interest of the researchers to hypothetical $\mathrm{C}_{60} \mathrm{H}_{60}$, instead of to real $\mathrm{C}_{20} \mathrm{H}_{20}$ can be, probably, is connected to huge, global attention to such unique (Nobel dignity) object as fullerene $\mathrm{C}_{60}$.

In present time it is possible already to speak, that the hopes of the researchers for creation of the storage of hydrogen on the basis of system fullerene $\left(\mathrm{C}_{60}\right)$ - fullerane $\left(\mathrm{C}_{60} \mathrm{H}_{60}\right)$ were not completely justified. The question, certainly, not that was not possible (all known methods of hydrogenation of fullerene $[1,2,5-8]$ and fullerite $[1,8,9])$ to synthesize fullerene of equiatomic (or even close to those) composition. Basically, fullerane $\mathrm{C}_{60} \mathrm{H}_{60}$ in heterogeneous heterophases reactions of hydrogenation crystalline fullerene it was impossible to synthesize, where, as it is well known, limiting always is the diffusion stage, in particular, the diffusion of hydrogen atoms through a layer of the formed product $\mathrm{C}_{60} \mathrm{H}_{\mathrm{x}}$. Even titanium hydride of stoichiometric composition $\left(\mathrm{TiH}_{2}\right)$ it fails to obtain, at least, at hydrogenation of metal in one stage. Though, titanium is a greatest hetter, in particular, of hydrogen. Fullerane with greatest possible (it is possible also of composition $\mathrm{C}_{60} \mathrm{H}_{60}$ ) contents of hydrogen, which is formed at fullerite hydrogenation on a surface of the division of phases of precursor and product, interferes further diffusion of atoms of hydrogen to some more not reacted part of fullerite. To obtain homogeneous under the contents of hydrogen a 
product adequate equiatomic composition $\mathrm{C}_{60} \mathrm{H}_{60}$, it is not represented, basically, possible from the point of view of the kinetics of heterogeneous reactions. The additional process of intensive mechanical dispergation of formed on a surface of division of phases of half-products is inevitable. However fullerite (or fullerane) is not titanium (or titanium hydride), and at its mechanochemical milling the destruction of bonds $\mathrm{C}-\mathrm{C}$ (defullerenization) will be observed. Therefore for more complete saturation fullerite by hydrogen process of the hydrogenation carried out at the increased temperatures and pressure [9], in particular, at temperatures is higher $550{ }^{\circ} \mathrm{C}$ and super-high pressure ( 2 GPa ) [1].

However to avoid the destruction of molecules of fullerene in so severe conditions of hydrogenation, naturally, not it is possible: the process of partial defullerenization of the closed carbon skeleton in $\mathrm{C}_{60}$ and $\mathrm{C}_{60} \mathrm{H}_{\mathrm{x}}$ with formation of the various size of unclosed hydrocarbon fragments $\mathrm{C}_{<60} \mathrm{H}_{\mathrm{x}}$ (for example, $\mathrm{C}_{58} \mathrm{H}_{\mathrm{x}}, \mathrm{C}_{56} \mathrm{H}_{\mathrm{x}}$ ) with the torn off bonds $\mathrm{C}-\mathrm{C}$ is observed [1]. Deactivation of these carbon radicals due to instant formation bonds $\mathrm{C}-\mathrm{H}$ can create the illusion of obtaining of highly hydrogenated fullerane (and even fullerene of equiatomic composition [1]). This partially defullerenizated fullerane in the chemical relation is closest, probably, to molecules of cycloalkanes (or polycycloalkanes), the strength of bonds $\mathrm{C}-\mathrm{H}$ in which approximately only twice is less than strength of bonds $\mathrm{C}-\mathrm{C}$. Therefore calculated energy of activation of dehydrogenation of fullerane is so high $(160 \mathrm{~kJ} / \mathrm{mol})$ [10]. However because of stress of bonds C-C in curved carbon skeleton of fragments $\mathrm{C}_{56} \mathrm{H}_{\mathrm{x}}$ should decrease not only values of strength of bonds $\mathrm{C}-\mathrm{C}$ and $\mathrm{C}-\mathrm{H}$, but also difference between these values. Therefore at temperatures $\left(>400{ }^{\circ} \mathrm{C}\right)$ of appreciable dehydrogenation of fulleranes $[11,12]$ the allocation of alkanes (methane, propane and butane) as products of destruction of a fullerene cage is indispensable observed also.

Hence, at realization any of convertible reactions in system fullerene-fullerane the destruction of molecules of precursor is fulfilled: at hydrogenatin the molecules of fullerene are collapsed, and at dehydrogenation - molecules of fullerane. According to [10] the energy of activation of fullerene hydrogenation only on $60 \mathrm{~kJ} / \mathrm{mol}$ less than the energy of activation of fullerene dehydrogenation $(160 \mathrm{~kJ} /$ $\mathrm{mol})$. Moreover, and this main, appreciable allocation of so necessary hydrogen owing to dehydrogenation of samples of fulleranes (for example, composition $\mathrm{C}_{60} \mathrm{H}_{36}$ ), synthesized by hydrogenation fullerene in solution by hydrogen at high pressure is fulfilled at too high $\left(>500^{\circ} \mathrm{C}\right)$ temperatures. Let's emphasize, that the so high temperatures of dehydrogenation are characteristic only for samples of fulleranes, obtained at stringent conditions of hydrogenation fullerene. Fullerane $\mathrm{C}_{60} \mathrm{H}_{36}$, which was synthesized from molecules of fullerene by Burch reduction, begins to dehydrogenate, according to [11], at much smaller temperature $\left(\sim 380^{\circ} \mathrm{C}\right)$. Moreover, in [10] was shown that partial (23\% of hydrogen from its general $(\mathrm{H}, 4.5 \%)$ contents in a sample is evacuated) dehydrogenation of fullerane in liquid naphthalene (mp
$80{ }^{\circ} \mathrm{C}$, bp $217.7^{\circ} \mathrm{C}$ ) and at the presence of the catalyst (dihydro irridium bisphosphine complex) already at temperature $225^{\circ} \mathrm{C}$ is realized.

Unfortunately, the researches on study of processes of fulleranes dehydrogenation in comparison with a number of the publications devoted to search and optimization of methods of synthesis of fullerenes and fulleranes, are extremely not numerous. Though, just, joint study of kinetics of processes of dehydrogenation and defullerenization of samples of fulleranes, prepared by various methods (in particular, by hydrogenation of fullerene or fullerite), is up very important for comparison and understanding of mechanisms of dehydrogenation and destruction fulleranes. In present time on the basis already of first experimental results it is possible to speak, that the temperatures of a beginning of fulleranes dehydrogenation and partial destruction of fullerene skeleton significantly depend on a method of samples synthesis. So, in [10] temperature $\left(400{ }^{\circ} \mathrm{C}\right)$ of dehydrogenation of crystalline fullerane was established on measurement in the closed chamber of pressure of allocated gas. However it is necessary to note, that the composition of volatile products of thermolysis of fullerene hydride in [10] was not investigated. In [11] by a thermogravimetric method was established, that the intensive loss of mass in fullerene hydride $\mathrm{C}_{60} \mathrm{H}_{36}$ essentially depends on a method of its obtaining. The reduction of mass of samples $\mathrm{C}_{60} \mathrm{H}_{36}$ prepared by reduction of fullerene by dihydroanthracene or Burch method is began at temperatures 510 and $380{ }^{\circ} \mathrm{C}$ accordingly. Besides a mass of a sample $\mathrm{C}_{60} \mathrm{H}_{36}$ (4.8 mass\% of hydrogen) obtained in the melt is decreased on 6.8 mass $\%$, whereas a mass of a sample $\mathrm{C}_{60} \mathrm{H}_{36}$, obtained in a solution by Burch reduction is decreased on 7.7 mass $\%$. As the loss of a mass in samples of fullerane $\mathrm{C}_{60} \mathrm{H}_{36}$ is significant (on 2-3\%) exceeds amount contained in it of hydrogen, the quite reasonable conclusion was made, that at thermolysis of fullerane there is an evacuation not only hydrogen, but also hydrocarbons as products of destruction of molecules of precursor. Really, in [12] by method of mass spectrometry was established, that in products of temperature-programmed desorption (TPD) deuterofullerite $\mathrm{C}_{60} \mathrm{D}_{19}$ are present, in particular, at temperatures 400 and $500{ }^{\circ} \mathrm{C}$, also (except for deuterium) deuteromethane and deuteropropane. Thus the authors [12] all peaks which have been found out in mass spectra with electron ionization (EI) of a gas phase above deuterofullerite $\mathrm{C}_{60} \mathrm{D}_{19}$, were explained due to the presence of only deuterium and fragments deuterocarbons. It is impossible to consider this conclusion rather correct, as in volatile products of thermodesorption of carbon materials [13, 14] and fullerene [14, 15] always contain also water, oxygen, $\mathrm{CO}$ and $\mathrm{CO}_{2}$. The peaks, for example, with $\mathrm{m} / \mathrm{z} 18$ and 28 can correspond to not only fragments $\left[\mathrm{CD}_{3}\right]^{+}$and $\left[\mathrm{C}_{2} \mathrm{D}_{2}\right]^{+}$, but also molecules $\mathrm{H}_{2} \mathrm{O}$ and $\mathrm{CO}$ accordingly. Therefore for an establishment of the mechanism fulleranes dehydrogenation it is necessary to study, in particular, by means of a mass spectrometric analysis the composition of volatile products of samples thermolysis, which are allocated at different stages of 
dehydrogenation and destruction of fulleranes obtaining different methods.

Thus, all techniques of obtaining of fulleranes [1, 2, 5-9] [which are developed for today on process of hydrogenation previously synthesized fullerene, fullerite or palladium fullerite are based. The sources of hydrogen such as polyamines, diimide, methanol, hydrides of metals, hydrogen, dihydroanthracene and others hydrocarbons, system $\mathrm{Zn}$-conc. $\mathrm{HCl}$ are varied only.

We believe that the search of the new approaches for development of more effective methods of synthesis of carbon molecules and their hydrogenated forms can appear more successful at detailed research of mechanisms not only of their formation, but also dehydrogenation and decomposition.

In the present paper the experimental results demonstrating, first of all, the possibility of obtaining in gram quantity of hydrogenated molecules of carbon, including fullerenes $\mathrm{C}_{60}$ and $\mathrm{C}_{70}$, essentially by other method excluding a technological stage of preliminary synthesis, in particular, fullerenes are submitted. Fulleranes and quasi-fulleranes [16-19] were synthesized directly from molecules of benzene and pyridine at the special method of heat treatment of them vapours. Here it is necessary to note, that in products of a new method of pyrolysis (NMP) of pyridine [16] and benzene [17-19] the carbon molecules of various types, such as fullerene $\mathrm{C}_{60}$, quasi-fulleranes $\mathrm{C}_{48}, \mathrm{C}_{44}$, $\mathrm{C}_{42}$ and $\mathrm{C}_{40}$, as well as small carbon molecules $\mathrm{C}_{3}-\mathrm{C}_{15}$ were found out also. Besides by mass spectrometric analysis was convincingly shown, that the hydrogen from products of pyrolysis both pyridine [16], and benzene [18, 19] is significantly evacuated at processing with their by laser. Here a basic attention will be given to study by means of mass spectrometric analysis of volatile substances (and, first of all, hydrogen), which are allocated in an interval of temperatures $30-750^{\circ} \mathrm{C}$ at different stages of dehydrogenation and destruction of hydrogenated molecules of carbon synthesized by NMP of pyridine and benzene. It is possible, that because of enough complex methods of fulleranes obtaining, providing always a stage of synthesis of fullerene, the researches (with mass spectrometric analysis of volatile products) of fulleranes thermostability in a wide interval of temperatures practically were not carried out.

\section{Materials and Methods}

New method of pyrolysis of pyridine (and also benzene) and its features are described by us earlier in [16-19]. The tests were carried out on installation basically typical for CVD of processes. One of the basic features NMP is, that the composition of obtained products depends not only on reactionary conditions (temperature, concentration of reagent, rate of a gaseous flow), but also place of localization of these products in reactionary space. At NMP a part of condensated substances and pyrolytic soot are taken out in a gas reactionary flow from a high-temperature zone A
(900-1000 $\left.{ }^{\circ} \mathrm{C}\right)$ and are located in more low-temperature zones $\mathrm{B}\left(<300{ }^{\circ} \mathrm{C}\right)$ and $\mathrm{C}\left(<70{ }^{\circ} \mathrm{C}\right)$. Depending on temperature in a zone A, concentration and time of stay in this zone of reagents changes not only the composition of products in zones $\mathrm{A}, \mathrm{B}$ and $\mathrm{C}$, but also their amount. In a zone A mainly pyrolytic soot is deposited which contains carbon nanostructures (nanotubes, nanofilaments, fibres, onions and toroids [20-21]), to which research all works connected to realization usual CVD of process are devoted practically.

Results of study of products of special heat treatment of vapours of both benzene, and pyridine, located only in zones $\mathrm{B}$ and $\mathrm{C}$ here are submitted. In these places of reactionary space, as firstly by us [16-19] was revealed, the carbon molecules of all types from a reactionary flow are condensed: fullerene $\mathrm{C}_{60}$, quasi-fullerenes $\mathrm{C}_{48}, \mathrm{C}_{40}$ and small carbon molecules (nanomolecules) $\mathrm{C}_{3}-\mathrm{C}_{15}$, as well as hydrogenated forms of these molecules. Is remarkable, that as Kroto was predicted [1], molecules smaller size, than $\mathrm{C}_{60}$ are steadiest as them hydrogenated forms: in mass spectra are detected mainly clusters, which can be correspond to such quasi-fullarenes as $\mathrm{C}_{20} \mathrm{H}_{14}-\mathrm{C}_{46} \mathrm{H}_{22}$.

To obtain the condensed products with the large contents of hydrogenated carbon molecules the tests on heat treatment of benzene and pyridine vapours were carried out under conditions, in particular temperatures, more favorable for processes of polymerization (instead of dehydropolymerization). We believe [18] that the stage of dehydrogenation of molecules of precursor, in particular, up to cluster $\mathrm{C}_{6}$, is necessary and limiting at radical reactions of formation of carbon molecules. Hydrogenated carbon molecules can be formed due to reactions of polymerization, for example, only of partially activated molecules of precursor. The products of several (8-10) tests obtained in each of zones under similar reactionary conditions were mixed up and then were exposed to careful processing in the beginning by benzene and then xylene for more complete extraction of the condensed substances. Dark-red colors of the extracts obtained from products of zones $\mathrm{B}$ and $\mathrm{C}$ were concentrated and then from them were deposited by ethanol powdery brick color deposits B1 and $\mathrm{C} 1$. The deposits BB1, $\mathrm{BC} 1$ and $\mathrm{PB} 1, \mathrm{PC} 1$ were obtained from products of pyrolysis benzene and pyridine accordingly.

Some part of powdery deposits again in toluene was dissolved. Prepared toluene solutions placed on a metal substrate and after evaporation of the solvent studied by a method of matrix-assisted laser (nitrogen, 337nm) desorption/ionization (MALDI) (Bruker Daltonics flexAnalysis). Analysis of thin structure of peaks (as was detailed described earlier $[16,18,19])$ for the majority of the clusters detected in mass spectra was investigated that has allowed more correctly to present the composition of detected molecules.

Powdery products investigated by methods chemical and $\mathrm{X}$-ray diffraction analysis, NMR and IR spectroscopy.

The composition of volatile products of thermal decomposition of powdery precipitation was investigated by 
a method temperature-programmed desorbtion mass spectrometry (TPDMS). Thermodesorption measurement was carried out on monopole mass spectrometer MX-7304A (Sumy, Ukraine) with impact electron ionization (EI) [22]. The samples at the bottom of molibdenium-quartz ampoule were evacuated at room temperature up to $5 \cdot 10^{-5} \mathrm{~Pa}$. The linear heating of a sample up to $750{ }^{\circ} \mathrm{C}$ was carried out with speed $0.15 \mathrm{~K} \cdot \mathrm{s}^{-1}$ ) [22]. The volatile thermolysis products passed through a high-vacuum valve $(5.4 \mathrm{~mm}$ in diameter) into the ionization chamber of the mass-spectrometer The ion currents of the desorption and thermolysis products were recorded with a secondary-electron multiplier VEU-6. Mass spectra were registered in a range 1-210 amu. TPD study was carried in the temperature range $20-750^{\circ} \mathrm{C}$, EI mass spectra were recorded when the temperature grows for every 5 degrees (at $20^{\circ} \mathrm{C}, 25^{\circ} \mathrm{C}, 30^{\circ} \mathrm{C}, 35^{\circ} \mathrm{C} \ldots 750^{\circ} \mathrm{C}$ ).

$\mathrm{X}$-ray diffraction study of powders was conducted on DRON-UM diffractometer with $\mathrm{Cu} \mathrm{K}_{\alpha}$-radiation and nickel filter.

The FTIR spectra in a reflectance mode were recorded in the range from 4,000 to $400 \mathrm{~cm}^{-1}$ with a spectral resolution of $8 \mathrm{~cm}^{-1}$ using a Nexus Nicolet FTIR spectrometer (Thermo Scientific) equipped with a Smart Collector reflectance accessory. Samples under investigation were powdered with $\mathrm{KBr}$ in $1: 10$ ratio.

NMR ${ }^{1} \mathrm{H}$ and ${ }^{13} \mathrm{C}$ studies were carried out using a universal AVANCE 400 spectrometer (Bruker, Germany). Solutions of sample in $\left(\mathrm{CH}_{3}\right)_{6} \mathrm{~N}_{3} \mathrm{PO}_{2} \mathrm{H}_{2} \mathrm{O}$ (hexamethylthreeamides of phosphorous acid (HMPA)) and $\mathrm{C}_{6} \mathrm{D}_{6}$ were placed in glass ampoules with $5 \mathrm{~mm}$ diameter; solids specimens were placed in rotors made from $\mathrm{ZrO}_{2}$ with $4 \mathrm{~mm}$ diameter (rotation speed at magic angle was $12 \mathrm{kHz}$ ). When determining chemical shifts $(\delta, \mathrm{ppm})$ in the NMR spectra, signals of tetramethylsilane and adamantane (CPMLS) were used.

\section{Results and Discussion}

Diffraction patterns of all deposited powdery products synthesized from vapours of benzene (BB1, BC1) and pyridine (PB1, PC1) practically are similar and testify about high X-ray amorphous of the given samples (Fig. 1). According to the chemical analysis all products, deposited by ethanol, alongside with carbon and oxygen always contain hydrogen, but contain it in different quantities. So samples PC1 (5.8 mass \%) and BC1 (4.9 mass \%) contain significantly more quantity of hydrogen, than in samples PB1 (3.9 mass \%) and BB1 (2.8 mass \%). Samples PB1 and PC1 contain also 2.7 and 3.4 mass \% of nitrogen accordingly. The contents of oxygen in all deposited samples usually does not exceed 3.1 mass \%. The most complete information on quantity and chemical state of hydrogen in the various synthesized samples can be received from mass spectrometric and thermodesorption researches, from features of structure IR and NMR spectra.

Earlier [17] by a mass spectrometric method MALDI was shown that the products of a zone $\mathrm{B}$ of benzene pyrolysis mainly consist from fulleranes $\mathrm{C}_{60} \mathrm{H}_{\mathrm{x}}$ (including fullerene of equiatomic composition, $\left.\mathrm{C}_{60} \mathrm{H}_{60}\right), \mathrm{C}_{70} \mathrm{H}_{\mathrm{x}}$ and $\mathrm{C}_{82} \mathrm{H}_{\mathrm{x}}$ of a various degree of hydrogenation. Mass spectra of a toluene solution of products of benzene pyrolysis of a zone $\mathrm{C}$ are submitted in Figures 2, 3. At a spectrum of the positively charged ions (Fig. 2A) there is a group of intensive peaks, in which the values $\mathrm{m} / \mathrm{z} 254,276,302,326,350,376,400,424$, $450,476,500,524,550$ and 574, change strictly on 24 or 26 units. From the spectra of the high resolution of each of these peaks follows, that the ratio of intensities in them of lines ${ }^{12} \mathrm{C}_{\mathrm{n}}$ and ${ }^{12} \mathrm{C}_{\mathrm{n}-1}{ }^{13} \mathrm{C}$ corresponds to natural isotope distribution of carbon for such molecules as: $\mathrm{C}_{20} \mathrm{H}_{14}, \mathrm{C}_{22} \mathrm{H}_{12}, \mathrm{C}_{24} \mathrm{H}_{14}$, $\mathrm{C}_{26} \mathrm{H}_{14}$ (Fig. 2B), $\mathrm{C}_{28} \mathrm{H}_{14}$ (Fig. 2B), $\mathrm{C}_{30} \mathrm{H}_{16}$ (Fig. 2A, inset), $\mathrm{C}_{32} \mathrm{H}_{16}, \mathrm{C}_{34} \mathrm{H}_{16}, \mathrm{C}_{36} \mathrm{H}_{18}, \mathrm{C}_{38} \mathrm{H}_{20}, \mathrm{C}_{40} \mathrm{H}_{20}, \mathrm{C}_{42} \mathrm{H}_{20}, \mathrm{C}_{44} \mathrm{H}_{22}$ и $\mathrm{C}_{46} \mathrm{H}_{22}$.

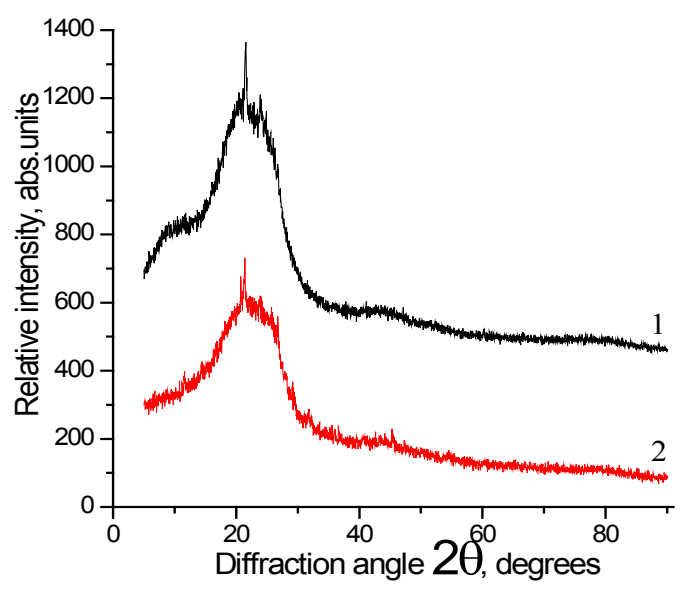

Figure 1. XRD patterns of samples: $1-\mathrm{PC} 1,2-\mathrm{BC} 1$

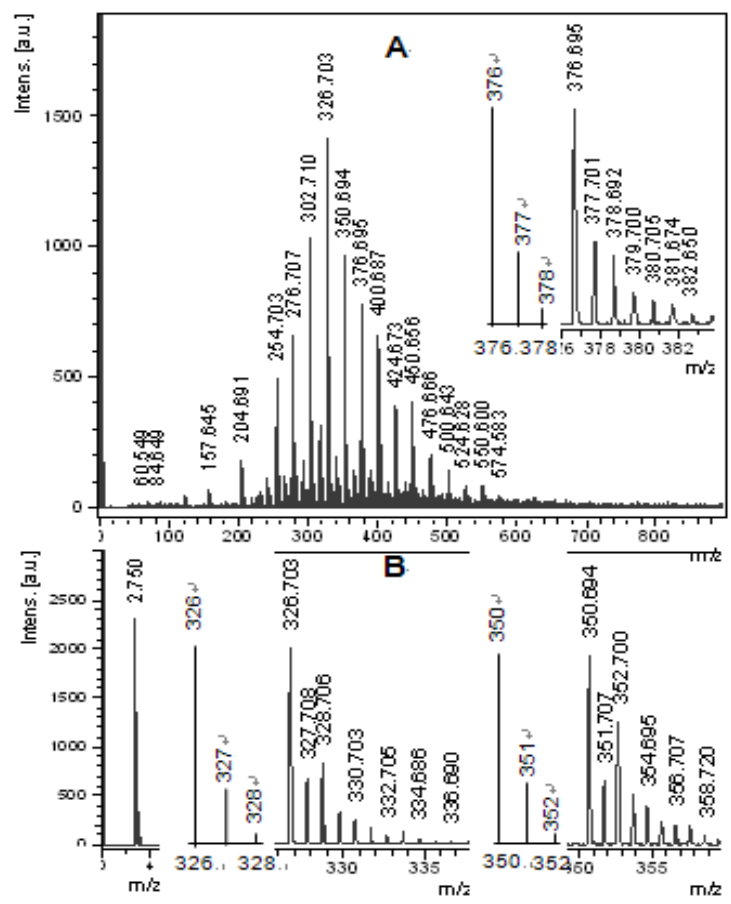

Figure 2. Cations mass spectrum of the product $\mathrm{BC} 1$ with the expansion around $\mathrm{m} / \mathrm{z} 376$ and the calculated isotope mass ratio for $\mathrm{C}_{30} \mathrm{H}_{16}$ molecule in the inset (Part A). The expansions around the $\mathrm{m} / \mathrm{z} 2-4 ; \mathrm{m} / \mathrm{z} 326,350$ peaks and the calculated isotope mass ratios for $\mathrm{C}_{26} \mathrm{H}_{14}, \mathrm{C}_{28} \mathrm{H}_{14}$ molecules respectively (Part B) 
It is possible, that the carbon molecules $\mathrm{C}_{20}-\mathrm{C}_{46}$, which do not answer a isolated pentagons rule (IPR), are more stably (as assumes Kroto [1]) as partially hydrogenated molecules, in particular of molecules of quasi-fulleranes of compositions $\mathrm{C}_{20} \mathrm{H}_{14}-\mathrm{C}_{46} \mathrm{H}_{22}$. However from thin spectra of all group of detected cations also precisely it is visible, that the lines ${ }^{12} \mathrm{C}_{\mathrm{n}-2}{ }^{13} \mathrm{C}_{2}$ considerably exceed accounted values of isotope distribution of carbon, characteristic for all above quasi-fulleranes. Therefore it is possible to consider, that in mass spectra are detected also more hydrogenated molecules quasi-fulleranes such as $\mathrm{C}_{20} \mathrm{H}_{16}-\mathrm{C}_{46} \mathrm{H}_{24}$. Really, from thin spectra (Fig. 2A, inset, Fig. 2B) it is possible distinctly to see, that each of the basic peaks represents a few peaks, which can be characteristic for more hydrogenated molecules of quasi-fulleranes. For example, the peaks with $\mathrm{m} / \mathrm{z} 326,350$ and 376 can correspond to quasi-fulleranes $\mathrm{C}_{26} \mathrm{H}_{14}-\mathrm{C}_{26} \mathrm{H}_{24}$, $\mathrm{C}_{28} \mathrm{H}_{14}-\mathrm{C}_{28} \mathrm{H}_{22}$ and $\mathrm{C}_{30} \mathrm{H}_{16}-\mathrm{C}_{30} \mathrm{H}_{22}$ accordingly. Hence, the molecules of quasi-fulleranes are sated with hydrogen, as a rule, more than on $50 \%$. Moreover, some molecules of quasi-fulleranes more than on $70-90 \mathrm{mass} \%$ are hydrogehated. And only molecules of fullerene $\mathrm{C}_{60}$ as steadiest of carbon molecules forms in the given reactionary conditions limiting sated by hydrogen fullerane $\mathrm{C}_{60} \mathrm{H}_{60}$. Extremely intensive dehydrogenation of researched products $\mathrm{BC} 1$ of benzene pyrolysis, observable at an irradiation by their laser, probably, is connected from the high contents of hydrogen in the synthesized carbon molecules: intensity of peak of hydrogen in a spectrum, for example, of positive ions (Fig. 2A, 2B) in some times exceeds intensity of all other peaks in mass spectra of a sample $\mathrm{BC} 2$. It is possible to assume, that the softer methods of mass spectrometry (for example, field desorption) can detect molecular clusters of quasi-fulleranes with the large contents of hydrogen, including quasi-fulleranes of equiatomic compositions.

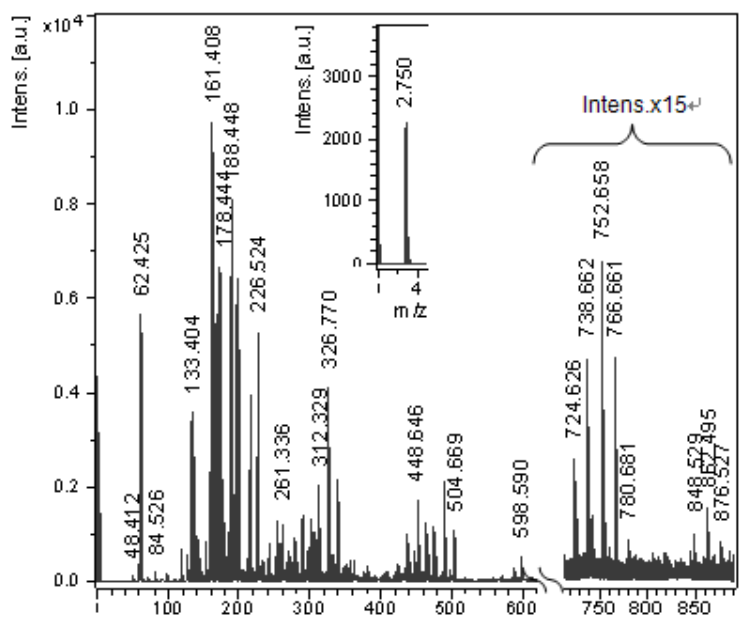

Figure 3. Anions mass spectrum of the product BC1 with $\mathrm{m} / \mathrm{z} 2-4$ region in the inset

In a spectrum of negative ions (Fig. 3) the peaks in a range $724-846 \mathrm{~m} / \mathrm{z}$ are most interesting. The thin spectra of peaks with $\mathrm{m} / \mathrm{z}$ 722, 738, 752, 766 and 780 completely answer isotope distribution in such molecules of fulleranes as $\mathrm{C}_{60} \mathrm{H}_{2}$,
$\mathrm{C}_{60} \mathrm{H}_{18}, \mathrm{C}_{60} \mathrm{H}_{32}, \mathrm{C}_{60} \mathrm{H}_{46}$ and $\mathrm{C}_{60} \mathrm{H}_{60}$. The thin spectra of peaks with $\mathrm{m} / \mathrm{z} 848,862$ and 876 correspond to fulleranes $\mathrm{C}_{70} \mathrm{H}_{8}$, $\mathrm{C}_{70} \mathrm{H}_{22}$ and $\mathrm{C}_{70} \mathrm{H}_{36}$. It is necessary to note, that the clusters appropriate to hydrogenated molecules of fullerenes $\mathrm{C}_{60}$ and $\mathrm{C}_{70}$ in a spectrum of positive ions are not detected at all. At the same time, at a spectrum of anions there are also rather intensive peaks with $\mathrm{m} / \mathrm{z} 62$ and 133, which can answer minimally hydrogenated carbon molecules $\mathrm{C}_{5}$ and $\mathrm{C}_{11}$. As was established by us earlier [16, 18, 19] the clusters of small carbon molecules and them hydrides most precisely are detected just as anions. Is remarkable, that in a spectrum of negative ions (Fig. 3) are absent (except for peak with $\mathrm{m} / \mathrm{z}$ 326) peaks, characteristic for partially hydrogenated quasi-fullerenes.

\subsection{Study of Volatile Products of Thermolysis}

From thermodesorption curves (Fig. 4, 5, 6, 7) follows that all 4 products of pyrolysis of benzene and pyridine not only contain hydrogen, as it was established also by means of the chemical analysis.

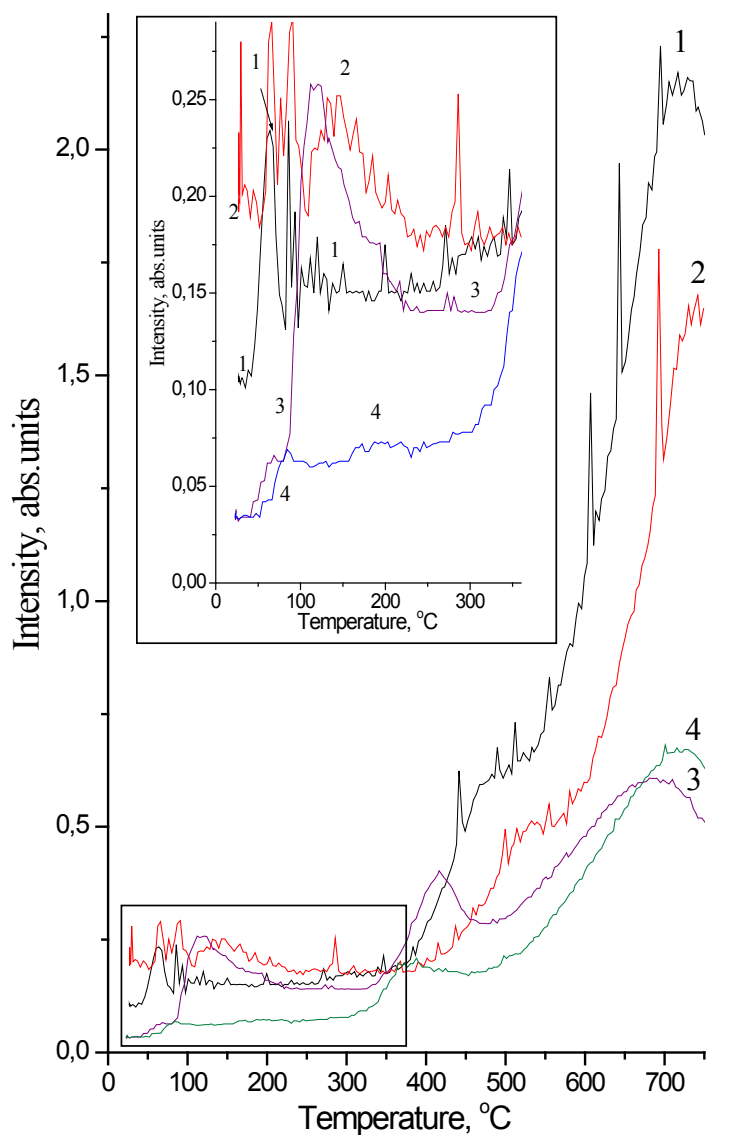

Figure 4. Experimental thermodesorption curves for the 3 amu peaks for samples: $1-\mathrm{PC} 1,2-\mathrm{BC} 1,3-\mathrm{PB} 1,4-\mathrm{B} \mathrm{B} 1$ with $25-350^{\circ} \mathrm{C}$ region in the inset

Notably, that its allocation is fulfilled out in all investigated temperature interval $\left(20-750^{\circ} \mathrm{C}\right)$, beginning (and it is surprising) with $50^{\circ} \mathrm{C}$. Moreover, from samples of a zone $\mathrm{C}(\mathrm{BC} 1$ and $\mathrm{PC} 1)$ the rather intensive allocation of 
hydrogen at lower $\left(25^{\circ} \mathrm{C}\right)$ temperature is started (Fig. 4, inset). Comparison of thermogram of desorption of hydrogen (Fig. 4) at thermolysis of identical mass ( $3 \mathrm{mg}$ ) of samples of zones $\mathrm{B}$ and $\mathrm{C}$ shown, that the contents of hydrogen in these samples essentially is differed. In products of a zone $\mathrm{C}$ is contained almost three times of hydrogen more, than in products of a zone B (Fig. 4). Thus, from a curves of temperature dependence of thermolysis of products BB1 and $\mathrm{BC} 1$ it is visible, that most intensive (as burst) the allocation of hydrogen at temperatures 80 and $400{ }^{\circ} \mathrm{C}$ is started. On curves of temperature dependence of thermolysis of products PB1 and PC1 three distinct maxima are visible which demonstrate three temperatures $\left(\sim 80,350\right.$ and $\left.500{ }^{\circ} \mathrm{C}\right)$ of beginning of the most intensive allocation of hydrogen. It is important here to specify, that the process of fulleranes dehydrogenation, which synthesized at hydrogenation of fullerenes, is observed only at temperatures above $400{ }^{\circ} \mathrm{C}$ $[10,11]$.

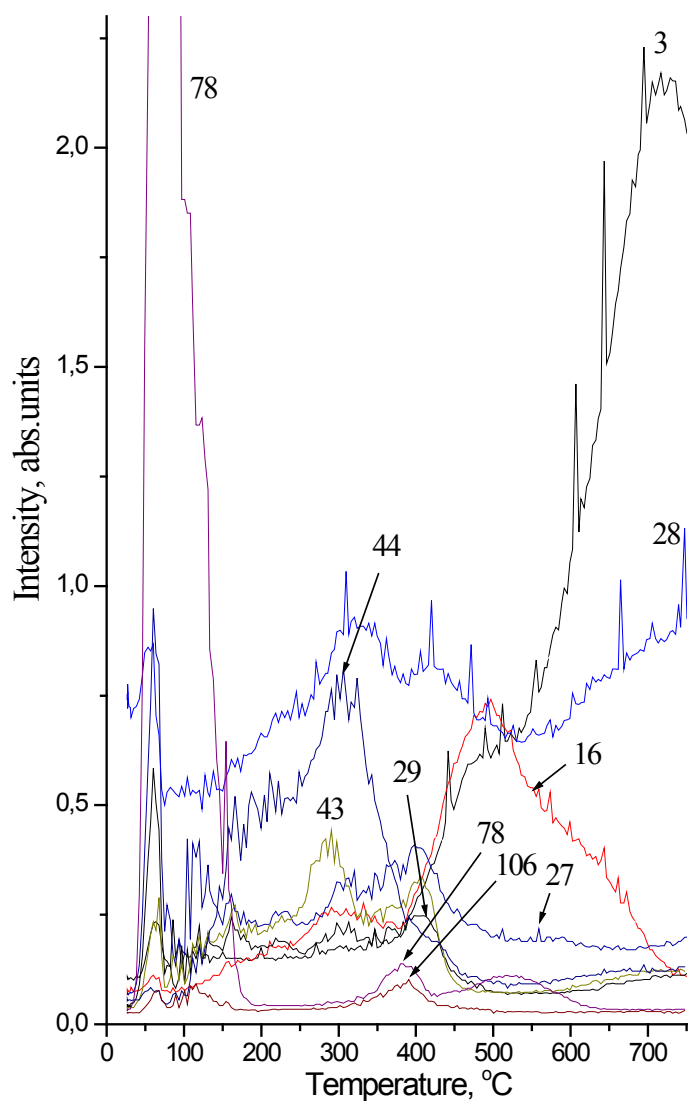

Figure 5. Experimental thermodesorption curves for selected 3, 16, 27, 28, $29,43,44,78$ and 106 amu peaks for the product $\mathrm{PC} 1$

Therefore it is possible to assume, that in the condensed products synthesized directly from benzene and pyridine and deposited (as and fullerenes) by ethanol, apart from fulleranes there are also other molecules of carbon, dehydrogenation which can be fulfilled at so low temperatures. On the other hand also it is possible, that particles of fulleranes of different dimensions are dehydrogenated (as it was established on samples of fulleranes, obtained by different ways [11]) at appreciable different temperatures. It is possible also, that heteroatomic, in particular, nitrogen containing molecules (polyazafullerenes [16]), which are present (as was established by us earlier) in samples PB1 and PC1, more easy are dehydrogenated. The higher intensity of low-temperature maxima of allocation of hydrogen on thermograms of samples PB1 and PC1 (in comparison with samples $\mathrm{BB} 1$ and $\mathrm{BC} 1$ ) can testify that the products of pyridine pyrolysis, containing polyazafullerenes [16], more easily are dehydrogenated.

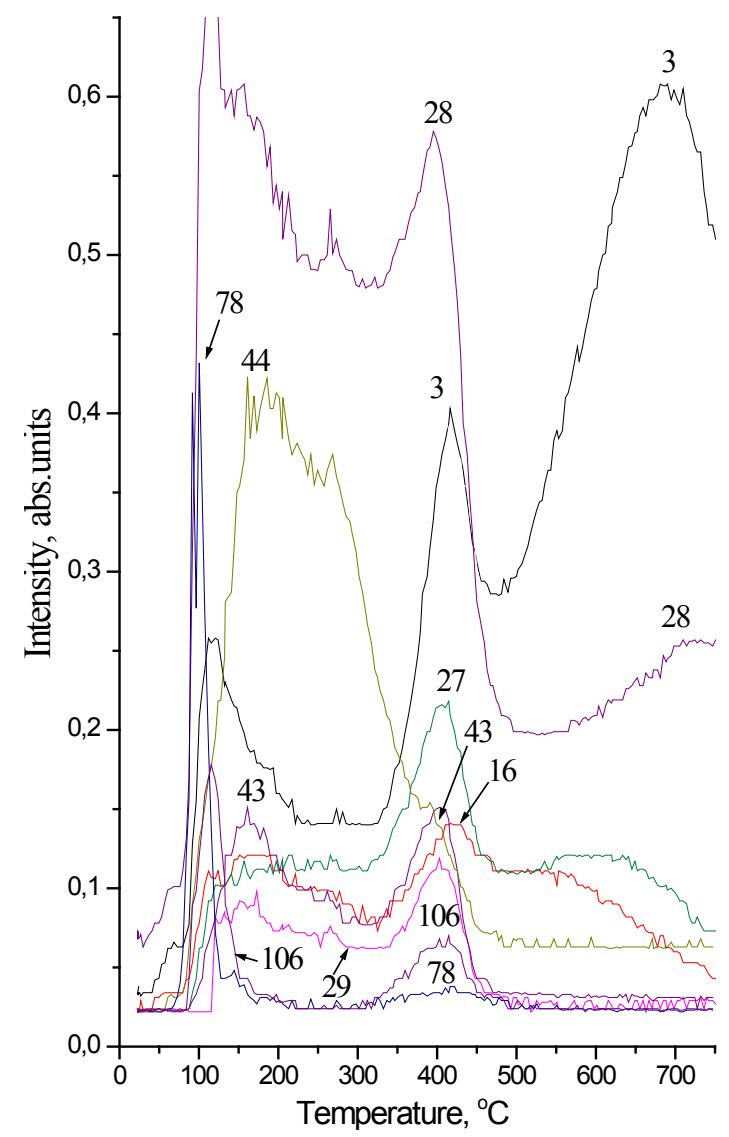

Figure 6. Experimental thermodesorption curves for selected 3, 16, 27, 28, 29, 43, 44, 78 and 106 amu peaks for the product PB1

Alongside with hydrogen in gaseous phase of thermolysis of all 4 condensed products of pyrolysis are detected methane, propane and butane, which on thermogram (Fig. 5, 6,7 ) are submitted characteristic (according to a database of mass spectra National Institute of Standards and Technology USA (NIST)) $100 \%$ by peaks of ions $\mathrm{CH}_{4}{ }^{+}, \mathrm{C}_{2} \mathrm{H}_{5}{ }^{+}$and $\mathrm{C}_{3} \mathrm{H}_{7}^{+}$ with $\mathrm{m} / \mathrm{z} \mathrm{16,29}$ and 43 accordingly. Here it is necessary to note, that the peak with $\mathrm{m} / \mathrm{z} 16$ corresponds not only to methane, but also is alongside with peaks with $\mathrm{m} / \mathrm{z} 18$ and 17 the third (on intensity) characteristic for mass spectrum of adsorbed water (peaks $\mathrm{H}_{2} \mathrm{O}$ with $\mathrm{m} / \mathrm{z} 18$ and 17 on given thermogram are not submitted). Water with $\mathrm{m} / \mathrm{z} 18,17$ and 16 as well as $\mathrm{CO}$ with $\mathrm{m} / \mathrm{z} 28$ and $\mathrm{CO}_{2}$ with $\mathrm{m} / \mathrm{z} 44$ as the products of oxidation in desorption mass spectra (EI) of carbon materials [14] always are present. The temperature interval of formation at thermolysis of methane is precisely 
observed on thermogram on an appreciable deviation of a maximum of peak with $\mathrm{m} / \mathrm{z} 16$ from maxima of peaks with $\mathrm{m} / \mathrm{z} 18$ and $\mathrm{m} / \mathrm{z} 17$, which belong to water. As it is possible to see (Fig. 5, 6,7) methane, propane and butane from products of pyrolysis of benzene and pyridine are allocated already at temperature $\sim 10{ }^{\circ} \mathrm{C}$. The intensity of allocation of propane and butane (in comparison with methane) in the initial moment of decomposition of fulleranes is higher. So, the temperature maxima of desorption of propane, butane and methane from a product $\mathrm{PC} 1$ are observed at temperatures 300, 400 and $500{ }^{\circ} \mathrm{C}$ accordingly (Fig. 5). The larger fragments of fulleranes destruction (butane and propane) are allocated at temperatures not above $400-450{ }^{\circ} \mathrm{C}$, whereas the allocation of methane proceeds up to temperature $750{ }^{\circ} \mathrm{C}$. It is necessary to note, that the destruction of a carbon skeleton of usual fulleranes with formation of hydrocarbons is started only at $400{ }^{\circ} \mathrm{C}[1,9]$.

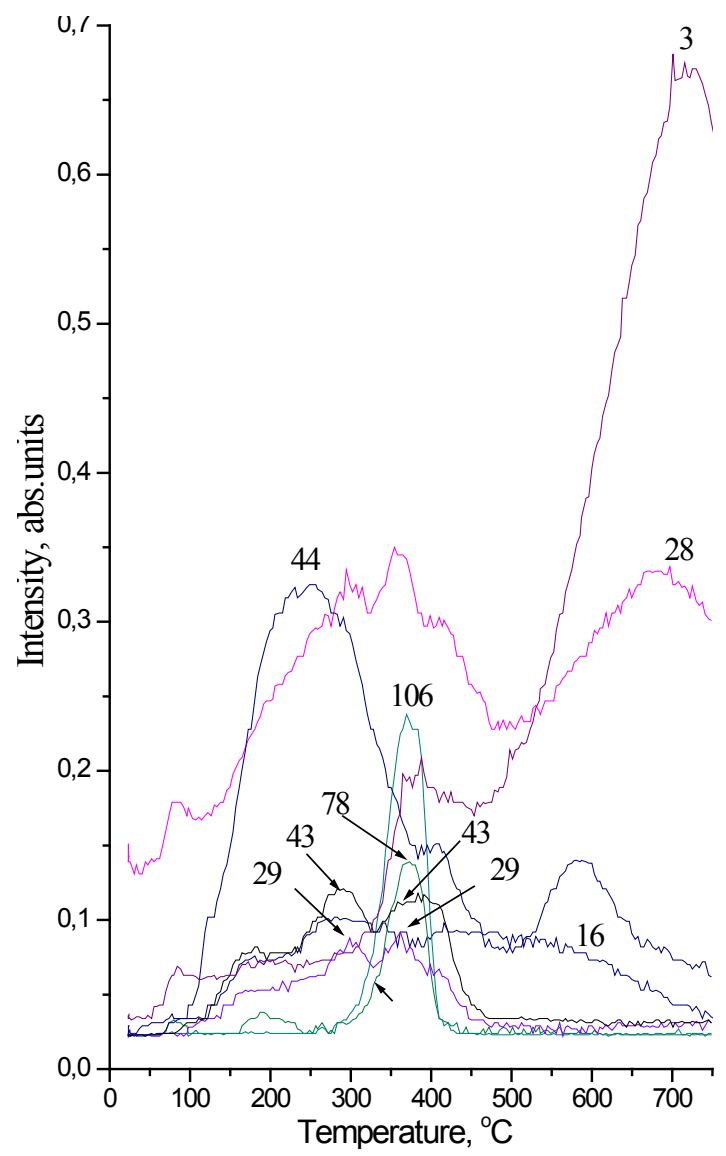

Figure 7. Experimental thermodesorption curves for selected 3, 16, 28, 29, 43, 44, 78 and 106 amu peaks for the product BB1

Notably, that the additional peak with $\mathrm{m} / \mathrm{z} 27$, which is characteristic for hydrocyanic acid $\mathrm{HCN}$, is detected in thermogram of products of pyridine pyrolysis. Allocation $\mathrm{HCN}$ from products PC1 (Fig. 5) and PB1 (Fig. 6) is observed practically in all a researched interval of temperatures $\left(100-750{ }^{\circ} \mathrm{C}\right)$. However, most intensive allocation $\mathrm{HCN}$ coincides with temperature $\left(\sim 450{ }^{\circ} \mathrm{C}\right)$ of destruction nitrogen containing carbon skeleton, at which methane, propane, butane and hydrogen are formed also. On thermogram of samples $\mathrm{C} 1$ and $\mathrm{B} 1$ practically in all investigated temperature interval the allocation of substances with $\mathrm{m} / \mathrm{z} 78$ and 106 is observed which (according to a database of mass spectra (NIST)) correspond to molecular ions of benzene and xylene. Most intensive desorption of molecules benzene and xylene is observed at low $\left(\sim 100^{\circ} \mathrm{C}\right)$ temperature that is connected to evaporation from powdery products of solvents used at extraction of condensed substances from pyrolytic soot. Desorption of the solvent (both benzene, and xylene) at higher temperatures $\left(350-400{ }^{\circ} \mathrm{C}\right)$ from products of pyrolysis $\mathrm{C} 1$ and $\mathrm{B} 1$ can occur due to decomposition of crystals solvates, which are formed by salting out by ethanol of carbon molecules from them benzene-xylene extracts. Desorption of molecules of ethanol is completely finished at temperatures below $100^{\circ} \mathrm{C}$.

\subsection{IR Spectra of the Condensed Products of Pyrolysis of Benzene and Pyridine}

The structures of IR spectra of powders PB1, PC1 and $\mathrm{BB} 1, \mathrm{BC}$, obtained from products of pyrolysis of pyridine and benzene accordingly, basically are similar and in many respects remind structures IR spectra of fulleranes of different compositions prepared by hydrogenation fullerenes $[2,7,8,23-29]$. So the values of the basic absorption bands in IR spectra of samples PB1 and BB1 (Fig. 8) are rather close to values established for fullerane $\mathrm{C}_{60} \mathrm{H}_{36}[2,7,8]$ and calculated for hypothetical $\mathrm{C}_{60} \mathrm{H}_{60}$ [30] (Table 1). (In the table designations of types of vibrations are used standard: ar - aromatic, st - stretching, $\delta$ - bending, ip - in plane, oop - out of plane, (1-9) $\mathrm{F}_{1 \mathrm{u}}$ - active vibration modes of bonds $\mathrm{C}-\mathrm{H}$ and $\mathrm{C}-\mathrm{C}$ fullerene cage calculated for $\mathrm{C}_{60} \mathrm{H}_{60}$ [30]). For highly symmetric $\left(\mathrm{I}_{\mathrm{h}}\right)$ fullerene $\mathrm{C}_{60}$ only four modes with symmetry $\mathrm{F}_{1 \mathrm{u}}$ are active in IR spectrum. Hydrogenation of fullerene lowers symmetry of obtained molecule of fullerane and, as the consequence, should be accompanied by activation of the vibrations, forbidden on symmetry. For most symmetric equiatomic composition fullerane $\mathrm{C}_{60} \mathrm{H}_{60}$ is calculated [30] 9 active modes three from which concern to vibrations bonds $\mathrm{C}-\mathrm{H}$ and 6 - to vibrations of fullerene cage. The molecules of partially hydrogenated fullerenes have smaller symmetry and, therefore IR spectrum, for example, $\mathrm{C}_{60} \mathrm{H}_{36}$, has greater number of bands (Table 1). According to structure of IR spectra of samples $\mathrm{PB} 1$ and $\mathrm{BB} 1$ it is possible to assume, that these products of pyrolysis contain mainly hydrogenated molecules of fullerenes. The absorption bands in IR spectra of samples PB1 and BB1, probably, responsible for vibrations of the deformed spherical skeleton of carbon molecules (Table 1), have the values 1594, 1461, 1166, 754, $453 \mathrm{~cm}^{-1}$ and 1600, 1453, 1145, 830, 698, $537 \mathrm{~cm}^{-1}$ accordingly. These absorption bands of samples PB1 and BB1 are closest to values of absorption bands of a carbon skeleton calculated for equiatomic fullerane $\mathrm{C}_{60} \mathrm{H}_{60}[30]$. The condensed products of pyrolysis of benzene according to mass spectrometric investigations [17] contain fulleranes with high contents hydrogen such as $\mathrm{C}_{60} \mathrm{H}_{46}, \mathrm{C}_{60} \mathrm{H}_{60}$ and $\mathrm{C}_{70} \mathrm{H}_{36}$. The band at $754(747) \mathrm{cm}^{-1}$, observable in IR spectra 
PB1 (BB1), is close to values 744 and $730 \mathrm{~cm}^{-1}$, characteristic for samples of fullerane $\mathrm{C}_{60} \mathrm{H}_{36}$, obtained by hydrogenation fullerene with use or $\mathrm{C}_{2} \mathrm{H}_{5} \mathrm{~J}$ [31] or $\mathrm{Zn}+$ conc. $\mathrm{HCl}$ [8]. The bands at 1594 and $1600 \mathrm{~cm}^{-1}$ can correspond to bonds $\mathrm{C}=\mathrm{C}$ in partially hydrogenated fullerane. In IR spectrum of a sample PB1 (obtained from pyridine) in comparison with IR spectrum of a sample BB1 (obtained from benzene) is contained greater amount of absorption bands in the range $1350-1700 \mathrm{~cm}^{-1}$. These additional bands can assign to bonds $\mathrm{C}-\mathrm{N}$, which are present in hydrogenated polyazafullerenes [16]. The band at $2222 \mathrm{~cm}^{-1}$, which is characteristic for bond $\mathrm{C} \equiv \mathrm{N}$, is precisely visible in IR spectrum of a sample PB1.

Characteristic for bonds $\mathrm{C}-\mathrm{H}$ stretching at 2922 and 2853 $\mathrm{cm}^{-1}$ and bending at $1377(1362) \mathrm{cm}^{-1}$ the vibrations in IR spectra of samples PB1 (BB1) will be satisfactorily coordinated with IR spectra of fullerenes hydrides obtained by different methods $[2,7,8]$ (Table 1 ). However the values of $\mathrm{C}-\mathrm{H}$ absorption bands are especially close for a sample BB1 and fullerane $\mathrm{C}_{60} \mathrm{H}_{36}$, obtained by a method Burch-Hückel [2,8] (Table 1). Extremely small intensity the band at $\sim 3050 \mathrm{~cm}^{-1}$, characteristic for stretching vibrations aromatic $\mathrm{C}-\mathrm{H}$ of bonds, testifies to insignificant presence at products of solvated aromatic solvents (benzene and xylene). Thus, the structures of IR spectra of products of pyrolysis of both benzene, and pyridine practically completely coincide with structure of IR spectra of various compositon fulleranes obtained at hydrogenation of fullerenes.

Table 1. Comparison of the main absorption bands in the IR spectra of samples PB1, BB1 and $\mathrm{C}_{60} \mathrm{H}_{36}[2,7,8]$ and calculated [23] for $\mathrm{C}_{60} \mathrm{H}_{60}$ values of the absorption bands

\begin{tabular}{|c|c|c|c|c|c|c|c|}
\hline \multirow{3}{*}{$\begin{array}{c}\text { Assignment of } \\
\text { IR absorption frequencies, } \\
\text { type of } \mathrm{C}_{60} \mathrm{H}_{\mathrm{x}} \text { cage and } \\
\mathrm{C}-\mathrm{H} \text { group } \\
\text { vibration }[30]\end{array}$} & \multicolumn{7}{|c|}{ Wavenumber $\left(\mathrm{cm}^{-1}\right)$} \\
\hline & \multicolumn{2}{|c|}{ Sample } & \multicolumn{4}{|c|}{$\begin{array}{c}\mathrm{C}_{60} \mathrm{H}_{36}, \mathrm{C}_{60} \text { hydrogenated by } \\
\text { followed reagent }[2,7,8]\end{array}$} & \multirow{2}{*}{$\begin{array}{c}\text { Calcu-lated for } \\
\mathrm{C}_{60} \mathrm{H}_{60} \\
{[30]}\end{array}$} \\
\hline & PB1 & BB1 & $\begin{array}{c}\mathrm{Li}+ \\
\mathrm{NH}_{3}^{+} \\
t-\mathrm{BuOH} \\
\end{array}$ & $\mathrm{C}_{2} \mathrm{H}_{5} \mathrm{~J}$ & $\begin{array}{l}\mathrm{Zn+} \\
\mathrm{HCl}\end{array}$ & $\begin{array}{c}\mathrm{Li}^{+} \\
\text {ethylene diamine+ } \\
\mathrm{t}-\mathrm{BuOH}\end{array}$ & \\
\hline $\begin{array}{c}9 \mathrm{~F}_{1 \mathrm{u}} \mathrm{sp}^{3} \mathrm{C}-\mathrm{H} \mathrm{st} \\
8 \mathrm{~F}_{1 \mathrm{u}} \mathrm{sp}^{3} \mathrm{C}-\mathrm{H} \mathrm{st} \\
\mathrm{sp}^{3} \mathrm{C}-\mathrm{H} \mathrm{st}\end{array}$ & $\begin{array}{l}2922 \\
2853\end{array}$ & $\begin{array}{l}2922 \\
2853\end{array}$ & $\begin{array}{l}2925 \\
2855\end{array}$ & $\begin{array}{l}2912 \\
2847 \\
2827\end{array}$ & $\begin{array}{l}2913 \\
2849\end{array}$ & $\begin{array}{l}2913 \\
2847 \\
2824\end{array}$ & $\begin{array}{l}2912 \\
2907\end{array}$ \\
\hline $\begin{array}{c}\mathrm{C}=\mathrm{C} \text { st } \\
7 \mathrm{~F}_{1 \mathrm{u}} \mathrm{C}_{60} \mathrm{H}_{\mathrm{x}} \text { cage } \\
\text { ar C-C st }\end{array}$ & $\begin{array}{l}1727 \\
1594\end{array}$ & 1600 & 1620 & $\begin{array}{l}1655 \\
1640 \\
1490\end{array}$ & $\begin{array}{ll}1725 & 1635\end{array}$ & $\begin{array}{l}1605 \\
1492\end{array}$ & 1612 \\
\hline $6 \mathrm{~F}_{1 \mathrm{u}} \mathrm{C}_{60} \mathrm{H}_{\mathrm{x}}$ cage & 1461 & 1453 & 1450 & 1460 & 1456 & 1453 & 1450 \\
\hline $5 \mathrm{~F}_{1 \mathrm{u}} \mathrm{C}-\mathrm{H} \delta$ & 1377 & 1362 & 1400 & 1448 & 1384 & & 1299 \\
\hline ar C-H ip & 1272 & & & & 1273 & & \\
\hline $4 \mathrm{~F}_{1 \mathrm{u}} \mathrm{C}_{60} \mathrm{H}_{\mathrm{x}}$ cage & 1166 & 1145 & & 1174 & 1123 & 1260 & 1163 \\
\hline ar C-C st & 1027 & - & & 1025 & $1073 \quad 1035$ & $\begin{array}{l}1097 \\
1024\end{array}$ & \\
\hline $\begin{array}{c}3 \mathrm{~F}_{1 \mathrm{u}} \mathrm{C}_{60} \mathrm{H}_{\mathrm{x}} \text { cage } \\
\text { ar C-H oop }\end{array}$ & $\begin{array}{l}887 \\
838\end{array}$ & $\begin{array}{l}830 \\
747\end{array}$ & & $\begin{array}{l}691 \\
667\end{array}$ & 730 & 803 & 885 \\
\hline $2 \mathrm{~F}_{1 \mathrm{u}} \mathrm{C}_{60} \mathrm{H}_{\mathrm{x}}$ cage & 754 & 698 & 675 & 526 & 678 & 697 & 487 \\
\hline $1 \mathrm{~F}_{1 \mathrm{u}} \mathrm{C}_{60} \mathrm{H}_{\mathrm{x}}$ cage & 453 & 537 & 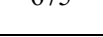 & 470 & & ד & 435 \\
\hline
\end{tabular}

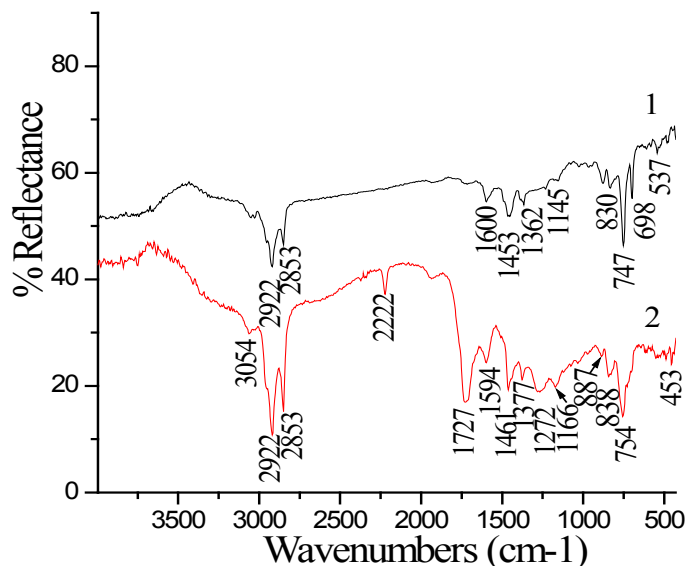

Figure 8. IR spectra of the products $1-\mathrm{BB} 1,2-\mathrm{PB} 2$ 


\subsection{NMR Spectra of Sample BB1}

In a spectrum of $\mathrm{NMR}{ }^{13} \mathrm{C}$ of a sample $\mathrm{BB} 1(100 \mathrm{MHz}$, $\mathrm{C}_{6} \mathrm{D}_{6},-1.0{ }^{\circ} \mathrm{C}, \mathrm{Me} 4 \mathrm{Si}$ ) (Fig. 9) two groups of signals distinctly are visible at $\delta 20-50$ и $125-140 \mathrm{ppm}$, which according to $[2,8,32]$ are characteristic for fullerene hydrides. (The signal with $\delta 128.064 \mathrm{ppm}$ assigns to $\mathrm{C}_{6} \mathrm{D}_{6}(\delta$ $=128.06$ ) as to the solvent [33]). The most intensive signals for atom of carbon in $\mathrm{sp}^{2}$ - state (Fig. 9) have the following values $\delta$ : $125.395,125.890,127.575,128.012,128.703$, $129.659,134.128,137.112,137.250$ and $143.708 \mathrm{ppm}$. A weak signal at $\delta 128.609 \mathrm{ppm}$ can belong to $\mathrm{sp}^{2}$ carbon of benzene $(\delta=128.62)$ [33], which, as is visible from Figure 9, participates in formation of crystal solvates. The most intensive signals with $\delta 20.820,20.820,28,698,32.839$, 38.789 and $48.374 \mathrm{ppm}$, characteristic for $\mathrm{C} \mathrm{sp}^{3}$ can belong to hydrogenated atoms of carbon in molecules of fulleranes. Apart from intensive signals in ${ }^{13} \mathrm{C}$ spectrum (Fig. 9) the group of weaker signals with $\delta 24.378,26.319,33.200$, $34.02035 .095,39.264 \mathrm{ppm}$ is observed which also are characteristic for $\mathrm{sp}^{3}$ carbon. Such plenty of signals for $\mathrm{C} \mathrm{sp}^{3}$ will be quite coordinated to the data of mass spectrometric analysis [17]: the product BB1 contains fulleranes of different compositions, in particular, equiatomic composition, $\mathrm{C}_{60} \mathrm{H}_{60}$.

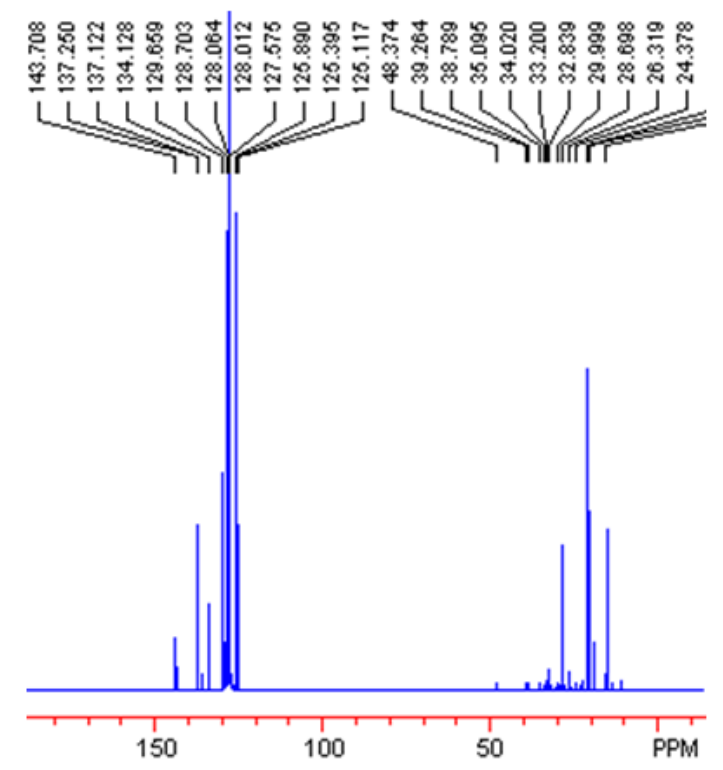

Figure 9. ${ }^{13} \mathrm{C}$ NMR spectrum $\left(100 \mathrm{MHz}, \mathrm{C}_{6} \mathrm{D}_{6},-1.0^{\circ} \mathrm{C}, \mathrm{Me}_{4} \mathrm{Si}\right)$ of product BB1

At a spectrum of NMR ${ }^{1} \mathrm{H}$ of sample BB1 $(400 \mathrm{MHz}$, HMPA, $-1.0{ }^{\circ} \mathrm{C}, \mathrm{Me}_{4} \mathrm{Si}$ ) there are most intensive signals with values $\delta 2.311,2.484,2.490,2.517,2.580,2.604,3.555$, $4.821 \mathrm{ppm}$, which are characteristic for hydrides of fullerenes $[2,8,32]$. The less intensive signals at $\delta 2,1-2,5$ ppm, observable also in a spectrum ${ }^{1} \mathrm{H}$ of a sample BB1, can correspond to, as suppose in $[11,34]$, fulleranes with the greater degree of hydrogenation, than well investigated fullerane $\mathrm{C}_{60} \mathrm{H}_{36}$. It is necessary also to note, that the extremely intensive signal ${ }^{1} \mathrm{H}$ from the solvent (HMPA) with $\delta 2.580 \mathrm{ppm}$ [33] coincides with signals from a researched BB1. A weak signal with $\delta 7.127 \mathrm{ppm}$ specifies presence benzene [26] at a sample, probably, in crystal solvates.

\section{Conclusion}

1. The new method of heat treatment of vapours of benzene and pyridine is developed: the molecules quasi-fulleranes $\left(\mathrm{C}_{20-46} \mathrm{H}_{14-44}\right)$ and fulleranes $\left(\mathrm{C}_{60} \mathrm{H}_{4}-\mathrm{C}_{60} \mathrm{H}_{60}\right.$ and $\left.\mathrm{C}_{70} \mathrm{H}_{8}-\mathrm{C}_{70} \mathrm{H}_{36}\right)$ are formed directly from molecules of benzene and pyridine at temperatures $900-1000^{\circ} \mathrm{C}$.

2. The new method of pyrolysis allows obtain molecules fulleranes $\left(\mathrm{C}_{60} \mathrm{H}_{32}, \mathrm{C}_{60} \mathrm{H}_{46}\right)$ and quasi-fulleranes $\left(\mathrm{C}_{26} \mathrm{H}_{24}\right.$, $\mathrm{C}_{28} \mathrm{H}_{22}, \mathrm{C}_{30} \mathrm{H}_{22}$ ) with unusual high (70-90 \%) degree of hydrogenation. Firstly a mass spectrometric method was detected a molecule of fullerane of equiatomic composition, $\mathrm{C}_{60} \mathrm{H}_{60}$.

3. Found that at heat treatment of vapours of benzene and pyridine the reactions of destruction of molecules of precursors with formation of small carbon molecules $\mathrm{C}_{3}-\mathrm{C}_{5}$, quasi-fulleranes $\left(\mathrm{C}_{40}, \mathrm{C}_{48}\right)$ and fullerene $\mathrm{C}_{60}$ is proceed also.

4. Intensive dehydrogenation of nanopowders quasi-fulleranes and fulleranes synthesized essentially by new method excluding a stage of obtaining fullerenes is began with temperature $\sim 50^{\circ} \mathrm{C}$ needs.

\section{REFERENCES}

[1] F. Cataldo, S. Iglesias-Groth. Fulleranes: The Hydrogenated Fullerenes, Springer, Dordrecht, 2010.

[2] R. E. Haufler, J. Conceicao, L. P. F. Chibante, Y. Chai, N. E. Byrne, S. Flanagan, M. M. Haley, S. C. O’Brien, C. Pan, Z. Xiao, W. E. Billups, M. A. Ciufolini, R. H. Hauge, J. L. Margrave, L. J. Wilson, R. F. Curl, R. E Smalley. Efficient Production of $\mathrm{C}_{60}$ (Buckminsterfullerene), $\mathrm{C}_{60} \mathrm{H}_{36}$, and the Solvated Buckide Ion, The Journal of Physical Chemistry, Vol.94, 8634-8636, 1990.

[3] H. W. Kroto, J. R. Heath, S. C. O'Brien, R. F. Curl and R. E. Smalley. $\mathrm{C}_{60}$ : Buckminsterfullerene, Nature, vol.318, No.6042, 162-163, 1985.

[4] L. A. Paquette, R. J. Ternansky, D. W. Balogh, G. Kentgen. Total synthesis of dodecahedrane, Journal of the American Chemical Society, Vol.105, No.16, 5446-5450, 1983.

[5] A. Peera, R. K. Saini, L. B. Alemany, W. E. Billups, M. Saunders, A. Khong, M. S. Syamala, R. J. Cross. Formation, Isolation, and Spectroscopic Properties of Some Isomers of $\mathrm{C}_{60} \mathrm{H}_{38}, \mathrm{C}_{60} \mathrm{H}_{40}, \mathrm{C}_{60} \mathrm{H}_{42}$ and $\mathrm{C}_{60} \mathrm{H}_{44}$, European Journal of Organic Chemistry, Vol.21, 4140-4145, 2003.

[6] K. Shigematsu, K. Abe, M. Mitani K. Tanaka. Catalytic Hydrogenation of Fullerenes in the Presence of Metal Catalysts in Toluene Solution, Fullerene Science and Technology. Vol.1, No.3, 309-318, 1993. 
[7] J. P. Zhang, N. X. Wang, Y. X. Yang. A. G. Yu. Hydrogenation of [60] fullerene with lithium in aliphatic amine, Carbon, Vol.42, No.3, 667-691, 2004.

[8] N. F. Goldshleger, A. P. Moravsky. Hydrides of the fullerenes, Uspekhi Khimii, Vol.66, No.4, 353-375, 1997. (Russian)

[9] A. V. Talyzin, A. Dzwilewski, B. Sundqvist, Y.O. Tsybin, J.M. Purcell, A.G. Marshall, Y.M. Shulga, C. McCammon, L. Dubrovinsky. Hydrogenation of $\mathrm{C}_{60}$ at $2 \mathrm{GPa}$ pressure and high temperature, Chemical Physics, Vol.325, 445-451, 2006.

[10] F. Chen, W. Li, R. Loutfy, R. Murphy, J. Wang. Hydrogen Storage in Fullerenes and in an Organic Hydride, Proceedings of the 1998 U.S. DOE Hydrogen Program Review, USA. 1998.

[11] A. A. Peera, Fullerene hydrides and studies toward the synthesis of fulvalenes. Ph.D.Thesis. Houston. Texas. 2004.

[12] Y. M. Shul'ga, B. P. Tarasov, V. N. Fokin. Deuterofullerenes, Carbon, Vol.41, No.7, 1365-1368, 2003.

[13] M. S. R. Zacharia. Desorption of gases from graphitic and porous carbon surfaces. Ph.D.Thesis. Free University of Berlin. 2004.

[14] T. Y. Gromovoy, B. B., Palyanytsya, V. A. Pokrovskiy, E. V. Basiuk, V. A. Basiuk. Interaction of thermally pretreated carbon nanomaterials with water vapor, Journal of Nanoscience and Nanotechnology, Vol.4, No.1-2, 77-81, 2004.

[15] M. Wohlers, A. Bauer, T. Belz, T. Rühle, T. Schedel-Niedrig, R. Schlögl. The Mechanism of Oxidation of Fullerenes with Molecular Oxygen, American Chemical Society Symposium Series, 108-112, 1996.

[16] A. Kharlamov, G. A. Kharlamova, M. E. Bondarenko. New products of a new method for pyrolysis of pyridine, Russian Journal of Applied Chemistry, Vol.86, No.2, 183-190, 2013.

[17] A. Kharlamov, M. E. Bondarenko, N. V. Kirillova. New method for synthesis of fullerenes and fullerene hydrides from benzene. Russian Journal of Applied Chemistry, Vol.85, 244-249, 2012

[18] A. Kharlamov, G. Kharlamova, M. Bondarenko, V. Fomenko. New method of generation of carbon molecules and clusters, Open Journal of Synthesis Theory and Applications, Vol.2. No.1, 38-45, 2013.

[19] A. Kharlamov, G. Kharlamova, M. Bondarenko. New Low-Temperature Method for Joint Synthesis of $\mathrm{C}_{60}$ Fullerene and New Carbon Molecules in the Form of $\mathrm{C}_{3}-\mathrm{C}_{15}$ and Quasi-Fullerenes $\mathrm{C}_{48}, \mathrm{C}_{42}, \mathrm{C}_{40}$. Russian Journal of Applied Chemistry, Vol.86, No.8, 1174-1183, 2013.

[20] A. I. Kharlamov, L. N. Ushkalov, N. V. Kirillova, V. V. Fomenko, N. I. Gubareny. Synthesis of onion nanostructures of carbon at pyrolysis of aromatic hydrocarbons, Reports of the National Academy of Sciences of Ukraine, Vol.3, 97-103, 2006. (Russian)

[21] A. I. Kharlamov, S. V. Loythenko, N. V. Kirillova, S.V. Kaverina, V. V. Fomenko. Toroidal nanostructures of carbon. Single-walled $4-, 5$ - and 6 hedrons and nanorings, Reports of the National Academy of Sciences of Ukraine, Vol.1, 95-100, 2004. (Russian)
[22] T. V. Kulik, V. N. Barvinchenko, B. B. Palyanitsa, O. V. Smirnova, V. K. Pogorelyi, A. A. Chuiko. A Desorption Mass Spectrometry Study of the Interaction of Cinnamic Acid with a Silica Surface, Russian Journal of Physical Chemistry A, Vol.81, No.1, 83-90, 2007.

[23] F. Cataldo, D. A. Garcia-Hernandez, A. Manchado, S. Iglesias-Groth. Spectroscopy of fullerenes, fulleranes and PAHs in the UV, visible and near infrared spectral range. Eds. J. Cami, N. Cox, The Diffuse Insterstellar Bands Proceedings IAU Symposium, No.297, 2013.

[24] K. Tokunaga. Hydrogenation of Fullerene $C_{60}$ : Material Design of Organic Semiconductors by Computation. In: Hydrogenation, Ed. I. Karamé, InTech, Chapter 13, 309-326, 2012.

[25] F. Cataldo, S. Iglesias-Groth, D. A. Garcia-Hernandez, A. Manchado. Determination of the Integrated Molar Absorptivity and Molar Extinction Coefficient of Hydrogenated Fullerenes, Fullerenes, Nanotubes, and Carbon Nanostructures, Vol.21, 417-428, 2013.

[26] S. M. Luzan, Y. O. Tsybin, A. V. Talyzin. Reaction of $\mathrm{C}_{60}$ with Hydrogen Gas: In Situ Monitoring and Pathways, The Journal of Physical Chemistry C, Vol.115, No.23, 11484-11492, 2011

[27] S. Iglesias-Groth, D. A. García-Hernández, F. Cataldo, A. Manchado. Infrared spectroscopy of hydrogenated fullerenes (fulleranes) at extreme temperatures, Monthly Notices of the Royal Astronomical Society, Vol.423, No.3, 2868-2878, 2012.

[28] S. M. Luzan, A. V. Talyzin. Effect of Catalysts on the Reaction of $\mathrm{C}_{60}$ with Hydrogen. Fullerenes, Nanotubes, and Carbon Nanostructures, Vol.20, No.4-7, 319-323, 2012.

[29] F. Cataldo, S. Iglesias-Groth, A. Manchado. On the Radical Cation Spectra of Fullerenes and Fulleranes. Part 2: $\mathrm{C}_{60} \mathrm{H}_{36}$, $\mathrm{C}_{70} \mathrm{H}_{38}, \quad \mathrm{C}_{60} \mathrm{H}_{18}$ and $\mathrm{C}_{60} \mathrm{H}_{\mathrm{x}} / \mathrm{C}_{70} \mathrm{H}_{\mathrm{y}}$ Mixture, Fullerenes, Nanotubes and Carbon Nanostructures, Vol.20, No.8, 672-680, 2012.

[30] R. Stoldt, R. Maboudian, C. Carraro. Vibrational Spectra of Hydrogenated Buckminsterfullerene: A Candidate for the Unidentified Infrared Emission, The Astrophysical Journal, Vol.548, 225-228, 2001.

[31] P. A. Dorozhko, A. S. Lobach, A. A. Popov, V. M. Senyavin, M. V. Korobov. Sublimation of hydrofullerenes $\mathrm{C}_{60} \mathrm{H}_{36}$ and $\mathrm{C}_{60} \mathrm{H}_{18}$. Chemical Physics Letters. Vol.336, No.1-2, 39-46, 2001.

[32] A. A. Gakh, A. Y. Romanovich. Thermodynamic Rearrangement Synthesis and NMR Structures of $\mathrm{C}_{1}, \mathrm{C}_{3}$, and T Isomers of $\mathrm{C}_{60} \mathrm{H}_{36}$. Vol.125, 7902-7906, 2003.

[33] G. R. Fulmer, A. J. M. Miller, N. H. Sherden, H. E. Gottlieb, A. Nudelman, B. M. Stoltz, J. E. Bercaw, K. I. Goldberg. NMR Chemical Shifts of Trace Impurities: Common Laboratory Solvents, Organics, and Gases in Deuterated Solvents Relevant to the Organometallic Chemist Organometallics, Vol.29, 2176-2179, 2010.

[34] K. Shigematsu, K. Abe, M. Mitani, K. Tanaka, Catalytic Hydrogenation Mechanism of Fullerenes in the Toluene Solution. Chemistry Express, Vol.8, 483-484, 1993. 